\title{
Nanoparticles of Selenium as Species with Stronger Physiological Effects in Sheep in Comparison with Sodium Selenite
}

\author{
Sirous Sadeghian • Gholam Ali Kojouri • \\ Abdonnaser Mohebbi
}

Received: 24 October 2011 / Accepted: 7 November 2011 /Published online: 30 November 2011

(C) The Author(s) 2011. This article is published with open access at Springerlink.com

\begin{abstract}
The present study was designed to compare the effects of nano red selenium and sodium selenite on the antioxidative activities of neutrophils and the hematological parameters in sheep. Fifteen sheep were randomly allocated into three groups. Groups 1 and 2 received selenium nanoparticles orally at $1 \mathrm{mg} / \mathrm{kg}$ and sodium selenite at $1 \mathrm{mg}$ $\mathrm{Se} / \mathrm{kg}$ for 10 consecutive days; group 3 served as the control. To assess the degrees of oxidative stress and of lipid peroxidation of the cellular membranes, the levels of thiobarbituric acid reactive substances (TBARS) were determined in serum samples that were collected at different supplementation intervals, i.e., after $0,10,20$, and 30 days. In addition, hematological parameters in the serum samples were measured by routine procedures. It was found that TBARS levels in groups 1 and 2 were significantly higher on days 20 and 30 compared to the basal level on day 0 . It was also found that on day 30, the TBARS activities in both treated groups were significantly higher than those of the controls $(P<0.05)$. These findings may explain the seemingly paradoxical effects of supplemental selenium on the indicators of oxidative stress, as the levels of TBARS were generally expected to decrease in the presence of selenium. There were no significant differences between the PCV and RBC values in the three groups. The white blood cell count (WBC) in group 1 showed a significant increase on days 20 and 30 in
\end{abstract}

\section{S. Sadeghian $(\triangle)$}

Department of Clinical Science, Faculty of Veterinary Medicine,

University of Tehran,

Tehran, Iran

e-mail: dr.sirous.sadeghian@gmail.com

\section{G. A. Kojouri · A. Mohebbi}

Department of Clinical Science, Faculty of Veterinary Medicine, University of Shahrekord,

Shahrekord, Iran comparison with the control group. However, in group 2, there was a significant increase of the WBC value just on day 20 in comparison with the control group. Also, there were significant increases of the neutrophil counts and significant decreases of the lymphocyte counts on day 10 in group 1, in comparison with those in group 2 and controls, and on days 20 and 30 in groups 1 and 2 in comparison with those in the control group.

Keywords Nano-selenium · Sodium selenite · TBARS · Hematological parameters $\cdot$ Sheep

\section{Introduction}

Selenium (Se) as a biocatalyst and functional component of numerous enzymes is needed for the proper functions of the immune system and possesses anticarcinogenic effects $[1,2]$. Se functions as a redox center of an array of selenoproteins $[3,4]$, such as glutathione peroxidase (GPx) [5, 6], phospholipid hydroperoxide glutathione peroxidase [7, 8], and thioredoxin reductase $[9,10]$. Nano-selenium (nano-Se) possesses equal efficacy in increasing the activities of GPx in plasma and liver from mice compared with selenomethionine [11]. Subsequent studies demonstrated that the activity of nano-elemental Se in upregulating selenoenzymes is comparable to that of selenite, selenomethionine, and methylselenocysteine, while exhibiting dramatically decreased acute toxicity [11-14]. Oxidative stress usually is defined as an increased formation of reactive oxygen species and/or decreased antioxidant defense. While cells and biological fluids have an array of protective antioxidant mechanisms, several methods for serum antioxidative activity determination have been developed. Most have been based on reduced production of thiobarbituric acid reactive substances 
(TBARS) [15]. What should be noted about the changes in hematological parameters is the effect of selenium on survivability of the RBCs. As a result, the present study was designed to determine hematological changes and the levels of oxidative stress and lipid peroxidation of cellular membrane changes in healthy sheep in response to selenium nanoparticles and sodium selenite supplementation using TBARS assay.

\section{Materials and Methods}

\section{Animals}

Fifteen healthy, 5- to 12-month-old Lori-Bakhtiari sheep were selected and randomly divided into three groups. The sheep were orally given nano red selenium (group I, $1 \mathrm{mg} / \mathrm{kg} \mathrm{BW}$ ) and sodium selenite (group II, $1 \mathrm{mg} \mathrm{Se} / \mathrm{kg} \mathrm{BW}$ ) for 10 consecutive days. The control group was given distilled water (group III).

\section{Ration}

During the study period, sheep were fed alfalfa hay and barely without selenium supplementation. The mean value of Se (mean $\pm \mathrm{SE}$ ) in the diet on dry matter basis was $0.49 \pm$ $0.15 \mathrm{mg} / \mathrm{kg}$.

\section{Nano Red Selenium Preparation}

Nano red elemental selenium particles (nano-Se) were synthesized as described previously by Zhang et al. [16]. The material includes $\mathrm{SeO}_{2}$ and ascorbic acid. The ascorbic acid solution was added into the aqueous solution of $\mathrm{SeO}_{2}$ to initiate the reaction. After the addition of ascorbic acid, nano red selenium particles began to form, causing the solutions to change from colorless to red. The red color of the ascorbic acid-treated solutions suggested that the selenium was present either in its amorphous or monoclinic forms [16]. The sizes of the obtained nano-Se particles ranged from 80 to $200 \mathrm{~nm}$ as determined by scanning electron microscopy.

\section{Sampling}

Two blood samples were collected from the jugular vein of sheep into acid-washed polyethylene tubes at the beginning of the experiment (day 0 ) and subsequently on days 10, 20, and 30. One tube contained heparin as the anticoagulation agent for hematological parameter analyses, and the other tube was without anticoagulation, for measuring TBARS.

\section{TBARS Assay}

Sample Preparation A serum sample of $0.5 \mathrm{ml}$ was mixed with $0.5 \mathrm{ml}$ sterile distilled water in a labeled $1.5-\mathrm{ml}$ micro- centrifuge tube. A blank sample (for calibration) was also prepared by adding $2 \mathrm{ml}$ of the reagent to $1 \mathrm{ml}$ distilled water.

Reagent Preparation Trichloroacetic acid (10\%) (w/v), $0.375 \%$ thiobarbituric acid (TBA) $(w / v)$, and $0.025 \mathrm{~N} \mathrm{HCl}$ were mixed and heated gently until TBA was dissolved completely.

Performing Assay Two milliliters of the reagent was added to each sample, and the microtubes were incubated in a boiling water bath for $10 \mathrm{~min}$. Then they were placed at room temperature for $15 \mathrm{~min}$ and centrifuged at $1,000 \times \mathrm{g}$ for $10 \mathrm{~min}$ at $4^{\circ} \mathrm{C}$. Finally, the supernatants were transferred to new labeled tubes, and absorbances of the samples were measured at $535 \mathrm{~nm}$ against a blank sample. Antioxidative activity was calculated by adding the malondialdehyde index $\left(1.056 \times 105 \mathrm{M}^{-1} \mathrm{~cm}^{-1}\right)$.

\section{Hematological Parameter Assay}

Hematological parameters including red blood cell (RBC) count, packed cell volume $(\mathrm{PCV})$ value, hemoglobin $(\mathrm{Hb})$ concentration, and white blood cell (WBC) counts were measured by routine procedures [17]. Hemoglobin was measured photometrically using the cyanomethemoglobin method, and PCV levels were determined using a microhematocrit centrifuge $(12,000 \times g$ for $5 \mathrm{~min})$. WBC measurement was conducted using the manual standard method. Differential leukocyte counts were performed on routinely prepared Geimsa-stained blood films using the cross-sectional technique [18].

\section{Statistical Analysis}

The results were analyzed statistically using the Sigma State (second version) program and by one-way analysis of variance tests. Also, the Tukey test and Dunnett's method were used for further evaluations at the level $P<0.05$.

\section{Results}

\section{TBARS}

The observed TBARS values in each group on different days of sampling are presented in Table 1. It should be noted that there were no significant differences in the TBARS values of the three groups at the beginning of the experiment (day 0) and on the 10th day, but a significant increase had occurred in groups 1 and 2 in comparison with the basal level on the 20th and 30th day $(P<0.05)$. In group 1 (nano-selenium), on the 20th and 30th day, the values of 
Table 1 The changes in mean + SD of TBARS value in each of the groups during the different days of sampling

\begin{tabular}{llll}
\hline $\begin{array}{l}\text { Sampling } \\
\text { days }\end{array}$ & $\begin{array}{l}\text { Group 1 } \\
\text { (nano-selenium) }\end{array}$ & $\begin{array}{l}\text { Group 2 } \\
\text { (sodium selenite) }\end{array}$ & Control \\
\hline 0 & $0.122 \pm 0.006$ & $0.125 \pm 0.007$ & $0.124 \pm 0.007$ \\
10 & $0.133 \pm 0.039$ & $0.146 \pm 0.118$ & $0.135 \pm 0.012$ \\
20 & $0.187 \pm 0.032^{*, * *}$ & $0.192 \pm 0.047^{*}$ & $0.145 \pm 0.027$ \\
30 & $0.184 \pm 0.012^{*, * *, * * *}$ & $0.199 \pm 0.035^{*, * * *}$ & $0.141 \pm 0.018$ \\
$P$ value & $<0.05$ & $<0.05$ & $>0.05$ \\
\hline
\end{tabular}

$* P<0.05$, significant increase to day $0 ; * * P<0.05$, significant increase to day $10 ; * * * P<0.05$, significant increase to the control group

TBARS were increased to $0.187 \pm 0.032$ and $0.184 \pm 0.012$, respectively $(P<0.05)$, in comparison with the basal level $(0.122 \pm 0.006)$. The statistical survey showed that there were no significant differences on the 10th day in comparison with day 0 , but a significant increase was observed in the values of TBARS on the 20th day in comparison with day $0(P=$ $0.002)$ and the 30th day compared with day $0(P<0.001)$. Besides, a significant increase was observed on the 20th $(P=$ $0.042)$ and 30th day $(\mathrm{P}=0.024)$ in comparison with the 10th day. These results show that the maximum values of TBARS occurred on day 20 and less antioxidant properties, in day 20. In group 2 (sodium selenite), TBARS value was increased slightly on the 10th day as it reached from $0.125 \pm$ 0.007 (day 0$)$ to $0.146 \pm 0.118$ on the 10 th day $(P>0.05)$. An ascending trend in TBARS value occurred on the 20th and 30th day and reached to $0.192 \pm 0.047$ and $0.199 \pm 0.035$, respectively $(P<0.05)$. A significant increase on the 20th day in comparison with day $0(P=0.013)$ and on the 30th day in comparison with day $0(P=0.002)$ was also seen. In the control group, there were no significant differences in the TBARS value on any of the sampling days, neither with the basal level (day 0) nor with each other. By comparing the means of the three groups together, it was determined that there were no significant differences in the TBARS values on the 0,10 th, and 20th day $(P>0.05)$, while in groups 1 and 2 , a significant increase in the TBARS values was seen just on the 30th day in comparison with the control group, with $P=0.003$ and $P=0.011$, respectively.

\section{Hematological Parameters}

The observed PCV, RBC, WBC, neutrophil, and lymphocyte counts in each group on different days of sampling are presented in Table 2, 3, 4, 5, and 6 .

\section{The PCV and RBC Counts}

In the three groups, there were no significant differences in the PCV and RBC counts on any of the sampling days, neither with the basal level (day 0 ) nor with each other.
Table 2 PCV counts (means $\pm \mathrm{SD}$ ) in each of the groups during the different days of sampling

\begin{tabular}{llll}
\hline $\begin{array}{l}\text { Sampling } \\
\text { days }\end{array}$ & $\begin{array}{l}\text { Group 1 } \\
\text { (nano-selenium) }\end{array}$ & $\begin{array}{l}\text { Group 2 } \\
\text { (sodium selenite) }\end{array}$ & Control \\
\hline 0 & $32.00 \pm 1.225$ & $30.400 \pm 1.517$ & $30.00 \pm 2.550$ \\
10 & $33.00 \pm 2.345$ & $30.800 \pm 2.950$ & $30.400 \pm 3.647$ \\
20 & $30.400 \pm 1.140$ & $31.600 \pm 3.782$ & $29.400 \pm 3.050$ \\
30 & $31.800 \pm 0.837$ & $28.400 \pm 3.286$ & $29.200 \pm 3.701$ \\
$P$ value & $>0.05$ & $>0.05$ & $>0.05$ \\
\hline
\end{tabular}

Number of WBC

In group 1 (nano-selenium), on the 10th and 20th day, the numbers of WBC increased to $8,640 \pm 879.204$ and 9,020 491.935, respectively $(P<0.05)$, in comparison with the basal level $(7,460 \pm 497.996)$. The statistical survey showed that there was a significant increase in WBC counts on the 10th, 20th, and 30th day in comparison with day 0 with $P=$ $0.031, P=0.002$, and $P=0.003$, respectively. As Table 4 clearly shows, in group 1 , the WBC counts decreased from the 20th day on, but statistically, there were no significant differences between the 20th and 30th day $(P>0.05)$. The statistical survey in group 2 (sodium selenite) showed that there was a significant increase on the 10th and 20th day in comparison to day 0 (the $P$ value was 0.045 and 0.023 , respectively), and unlike group 1, there was no significant difference in the 30th day in comparison to day 0 . In the control group, there were no significant differences in the WBC counts on any of the sampling days, neither with the basal level (day 0) nor with each other. By comparing the means of the three groups together, it was determined that there were no significant differences in the WBC counts on day $0(P>0.05)$. The WBC counts in group 1 showed a significant increase on the 20th and 30th day in comparison with the control group (the $P$ value was 0.001 and 0.021 , respectively), while in group 2 , a significant increase in the WBC counts was seen just on the 20th day in comparison with the control group $(P=0.047)$.

Table 3 Red blood cell counts (means \pm SD) in each of the groups during the different days of sampling

\begin{tabular}{llll}
\hline $\begin{array}{l}\text { Sampling } \\
\text { days }\end{array}$ & $\begin{array}{l}\text { Group 1 } \\
\text { (nano-selenium) }\end{array}$ & $\begin{array}{l}\text { Group 2 } \\
\text { (sodium selenite) }\end{array}$ & Control \\
\hline 0 & $11.300 \pm 0.412$ & $10.820 \pm 0.492$ & $10.660 \pm 0.853$ \\
10 & $11.660 \pm 0.811$ & $10.900 \pm 0.935$ & $10.820 \pm 1.260$ \\
20 & $10.780 \pm 0.432$ & $11.220 \pm 1.248$ & $10.520 \pm 1.040$ \\
30 & $11.240 \pm 0.288$ & $10.120 \pm 1.117$ & $10.380 \pm 1.184$ \\
$P$ value & $>0.05$ & $>0.05$ & $>0.05$ \\
\hline
\end{tabular}


Table 4 White blood cell counts (means \pm SD) in each of the groups during the different days of sampling

\begin{tabular}{llll}
\hline $\begin{array}{l}\text { Sampling } \\
\text { days }\end{array}$ & $\begin{array}{l}\text { Group 1 } \\
\text { (nano-selenium) }\end{array}$ & $\begin{array}{l}\text { Group 2 } \\
\text { (sodium selenit) }\end{array}$ & Control \\
\hline 0 & $7,460 \pm 497.996$ & $7,420 \pm 449.444$ & $7,440 \pm 602.495$ \\
10 & $8,640 \pm 879.204^{*}$ & $8,380 \pm 785.493^{*}$ & $7,560 \pm 795.613$ \\
20 & $9,020 \pm 491.935^{*, * *}$ & $8,540 \pm 931.665^{*, * *}$ & $7,420 \pm 521.536$ \\
30 & $8,580 \pm 349.285^{*, * *}$ & $8,100 \pm 768.115$ & $7,500 \pm 768.115$ \\
$P$ value & $<0.05$ & $<0.05$ & $>0.05$ \\
\hline
\end{tabular}

$* P<0.05$, significant increase to day $0 ; * * P<0.05$, significant increase to the control group

\section{The Neutrophil Counts}

Table 5 shows that the number of neutrophils in groups 1 and 2 increased in the period between days 0 and 20, but this increase was more significant in the nano-selenium group (the $P$ value was $<0.001$ in each of the three groups). The statistical survey in group 1 (nano-selenium) showed that there was a significant increase in neutrophil counts on the 10th, 20th, and 30th day in comparison with day 0 (the $P$ value was $<0.001$ in each of the three groups), on the 20th day in comparison with the 10th day $(P=0.005)$, and on the 30 th day in comparison with the 10th day $(P=0.015)$. In group 2 (sodium selenite), there was significant increase on the 10th, 20th, and 30th days in comparison with day 0 (the $P$ value was $0.019,<0.001$, and 0.003 , respectively) and on the 20th day in comparison with the 10th day $(P=0.003)$, but unlike group 1, there was no significant difference on the 30th day in comparison to the 10th day. In the control group, there were no significant differences in the neutrophil counts on any of the sampling days, neither with the basal level (day 0) nor with each other. By comparing the means of the three groups together, it was determined that there were no significant differences in the neutrophil counts on day $0(P>$ 0.05 ). The neutrophil counts in group 1 showed a significant increase on the 10th day in comparison with the two groups $(P=0.050)$ and control $(P=0.049)$ group, on the 20th and 30th

Table 5 Neutrophil counts (means \pm SD) in each of the groups during the different days of sampling

\begin{tabular}{llll}
\hline $\begin{array}{l}\text { Sampling } \\
\text { days }\end{array}$ & $\begin{array}{l}\text { Group 1 } \\
\text { (nano-selenium) }\end{array}$ & $\begin{array}{l}\text { Group 2 } \\
\text { (sodium selenite) }\end{array}$ & Control \\
\hline 0 & $33.200 \pm 1.924$ & $32.400 \pm 1.817$ & $34.200 \pm 2.864$ \\
10 & $43.200 \pm 3.701^{*, * * *, * * * * * *}$ & $37.800 \pm 3.701^{*}$ & $35.00 \pm 7.00$ \\
20 & $63.00 \pm 10.840^{*, * *, * * * * *}$ & $55.200 \pm 8.289^{*, * *, * * * * *}$ & $36.400 \pm 1.517$ \\
30 & $53.800 \pm 6.686^{*, * *, * * * * *}$ & $44.600 \pm 6.387^{*, * * * * *}$ & $34.400 \pm 2.510$ \\
$P$ value & $<0.05$ & $<0.05$ & $>0.05$ \\
\hline
\end{tabular}

$* P<0.05$, significant increase to day $0 ; * * P<0.05$, significant increase to day $10 ; * * * P<0.05$, significant increase to group 2 (sodium selenite); $* * * * P<0.05$, significant increase to the control group
Table 6 Lymphocyte counts (means \pm SD) in each of the groups during the different days of sampling

\begin{tabular}{llll}
\hline $\begin{array}{l}\text { Sampling } \\
\text { days }\end{array}$ & $\begin{array}{l}\text { Group 1 } \\
\text { (nano-selenium) }\end{array}$ & $\begin{array}{l}\text { Group 2 } \\
\text { (sodium selenite) }\end{array}$ & Control \\
\hline 0 & $63.800 \pm 1.924$ & $65.400 \pm 0.894$ & $63.800 \pm 2.588$ \\
10 & $53.600 \pm 3.507^{*, * * * *, * * * * * *}$ & $59.800 \pm 2.168^{*}$ & $62.200 \pm 6.723$ \\
20 & $34.200 \pm 10.498^{*, * *, * * * * * *}$ & $41.800 \pm 9.230^{*, * *, * * * * * *}$ & $61.800 \pm 2.775$ \\
30 & $34.200 \pm 10.498^{*, * *, * * * * * *}$ & $53.400 \pm 6.107^{*, * * *, * * * * * *}$ & $63.600 \pm 2.881$ \\
$P$ value & $<0.05$ & $<0.05$ & $>0.05$ \\
\hline
\end{tabular}

$* P<0.05$, significant reduction to day $0 ; * * P<0.05$, significant reduction to day $10 ; * * * P<0.05$, significant increase to day 20 ; $* * * * P<0.05$, significant reduction to group 2 (sodium selenite); $* * * * * P<0.05$, significant reduction to the control group

day compared with control group (the $P$ value was $<0.001$ and $<0.001$, respectively), and in group 2 on the 20th and 30th day (the $P$ value was 0.001 and 0.010 , respectively) in comparison with the control group.

\section{Number of Lymphocytes}

Table 6 shows that the number of lymphocytes in groups 1 and 2 decreased in the period between days 0 and 20, but this decrease was more significant in the sodium selenite group (the $P$ value was $<0.001$ in each of the three groups). The statistical survey in group 1 (nano-selenium) showed that there was a significant decrease in lymphocyte counts on the 10th, 20th, and 30th day in comparison with day 0 (the $P$ value was $<0.001$ in each of the three groups), on the 20th day in comparison with the 10th day $(P=0.004)$, and on the 30th day in comparison with the 10th day $(P=$ 0.030 ). In group 2 (sodium selenite), there was significant decrease on the 10th, 20th, and 30th day in comparison with day 0 (the $P$ value was $<0.001,<0.001$, and 0.002 , respectively) and on the 20th day in comparison with the 10th day $(P=0.003)$, but unlike group 1 , there was no significant difference on the 30th day in comparison to the 10th day, but in group 2, there was significant increase on the 30th day in comparison to the 20th day $(P=0.047)$. In the control group, there were no significant differences in the lymphocyte counts on any of the sampling days, neither with the basal level (day 0) nor with each other. By comparing the means of the three groups together, it was determined that there were no significant differences in the lymphocyte counts on day $0(P>0.05)$. The lymphocyte counts in group 1 showed a significant decrease on the 10th day in comparison with those in group $2(P=0.010)$ and the controls $(P=0.035)$ and in group 1 on the 20th and 30th day, in comparison with the control group, with $P$ values of $<0.001$ and $<0.001$, respectively, and in group 2 on the 20th and 30th day, in comparison with the control group, with $P$ values of 0.002 and 0.010 , respectively. 


\section{Discussion}

Se is important for the control of oxidative stress and therefore the redox state of the cell, due to its incorporation as selenocysteine to GSH-Px [19] and thioredoxin reductase [20]. Selenium, as an essential micronutrient in animals, has three levels of biological activities: (1) trace levels are required for normal growth and development, (2) nutritional and supranutritional levels can be stored, and homeostatic functions will be maintained, and (3) toxic levels can result in harmful effects [21]. TBARS in biological specimens, including lipid hydroperoxides and aldehydes, increase as a result of oxidative stress. Indeed, plasma concentrations of TBARS are an index of lipid peroxidation and oxidative stress. TBARS return to normal levels over time, depending upon the antioxidants [22, 23]. In this study, the TBARS value in group 1 (nanoselenium) was reduced after the 20th day, but in group 2 (sodium selenite), the TBARS value was in a high level till the 30th day. Therefore, in group 2, the return of TBARS to the basal level has been done with more delay, and it shows the better antioxidative activity of selenium nanoparticles in comparison with sodium selenite. Kumar et al. indicated that Se had no effect on serum total protein, albumin/globulin ratio, and SGPT and SGOT activities but could increase the capacity of the immune system to protect cells from free radical injuries [24]. Huang et al. showed that the elemental Se nanoparticles have significant effects on both the scavenging of the free radicals and the protection of DNA against oxidation, dependent upon size: the smaller, the better [25]. The major result of increasing phagocytic activities of polynuclear cells, especially neutrophils, which are the first body defensive barriers, is an increase in oxidative pressure [26]. Also, respiratory burst, which occurred in neutrophils, can release oxygen free radicals that play a major role in pathogenesis of foreign agents. When neutrophils interact with foreign agents, hundreds of times more oxygen may be released than in their resting state. This causes increasing activation of the NADPH oxidase enzyme on the cell surface. Toxic materials that are produced in neutrophils are severely destructive and cause neutrophil membrane destruction. Selenium admixtures can prevent destruction by elimination of toxic materials and free radicals and can reduce toxic material production of neutrophils, lipid peroxidation, and TBARS values [27-29]. Zhang et al. indicated that nano-Se had a weaker interference effect than selenite on antioxidative balance in Se-deficient mice [13]. Selenium, as the functional component of GSH-Px, protects the neutrophils and other blood components against peroxidative damage [27]. Fraga has mentioned that selenium deficiency can increase oxygen free radicals in body tissues [28], the major negative effects of which are on the consistency of biological membranes and the performance of immunity cells [30]. Heyland has suggested selenium meal consumption as a protective antioxidative activity and a way of decreasing acute disease mortality [31]. Selenium is involved in selenoprotein-type structures which include glutathione peroxidase [32], P selenoprotein, and W selenoprotein. These proteins have a protective role against oxidant materials in body cells and cause an increase in the body's cell resistance such as immunity cells against oxidative destruction [33, 34]. In a study, Zhou et al. indicated discrepancy of muscle Se concentration and GSH-Px activity is because only a part of nano-Se was adopted for selenoprotein synthesis and another metabolic pathway of nano-Se differing from sodium selenite and selenomethionine may exist [35]. The most important action $\mathrm{Se}$ is its antioxidant effects because it forms selenocysteine, part of the active center of the GPx [36, 37]. GPx is the most important peroxidase for the detoxification of hydroperoxides and lipidic hydroperoxides at the level of the cytosol and mitochondrial matrix [38, 39]. Nano-Se increased the GST activity more efficiently than selenomethionine [11]. The higher antioxidative activity of nano-Se is further evident from the observed decline of the hepatic superoxide dismutase (SOD) activity. Furthermore, nano-Se exhibits stronger inhibitory effects than selenite and simultaneously increases the hepatic GSH (reduced glutathione) concentrations, while no apparent alteration of the GSH levels were observed with selenite [40]. Since SOD and GSH are indicators of oxidative stress, this demonstrates the advantages of nano-Se over other forms of the element. What should be noted about the changes in hematological parameters is the effect of selenium on survivability of the RBCs [41]. Fraga and Lessard have recognized selenium deficiency as a factor in preventing the activity of glutathione peroxidase and increasing the free oxygen radicals in the tissues such as RBCs, which leads to increase the oxidative damage of the tissues [28, 30]. Although the role of selenium in increasing the resistance of the RBCs has been proved and its deficiency has been mentioned as a factor in anemia production, this effect has not been significant when studying the hematological profile in the present study, and the number of RBCs and the hematocrit value in the group getting nano-selenium have been a little more than group 2 (sodium selenite) and the control group, but not statistically significant. It should be mentioned about the changes in the number of neutrophils, lymphocytes, and WBCs, that the type of body immunity system response and the leukogram changes would be different depending on the kind of animal, individual differences, the kind of animal's nutrition, the grade of the animal's involvement, the 
presence of stress, etc. [42]. Another conclusion that has been obtained about the effect of selenium on blood cells is increasing the number of the cells (WBCs and neutrophils) and maintaining them in a high level for a longer period of time, so that nano-selenium has affected more severely than sodium selenite. The cause is the role of selenium as an anti oxidant and its ability to take care of body cells against antioxidative damages [27]. The researchers know selenium deficiency is an effective factor on the reduction of the lymphocyte reproductive potency and mention that the importing receptor of transferrin (which is effective in the reproduction of lymphocytes) will be reduced in the animals having selenium deficiency [43]. So, the researchers believe that selenium deficiency results in the weakness of immunity system by preventing the lymphocytes reproduction [30]. What should be noted here is that in all of the mentioned researches, selenium has played a role as an additive factor in increasing the lymphocyte reproduction, but according to the results of the present research, the number of lymphocytes has been decreased until the 20th day of responding nano-selenium and sodium selenite. To analyze this event, the role of neutrophils as the first defensive barrier of the body should be noted. An external material can activate specified immunity system when it passes through the intrinsic immunity barrier and is given to specified immunity system as an antigen, therefore not increasing the number of lymphocytes in the present study can be related to significant increase in the number of neutrophils and not encountering of the lymphocytes with any kind of stimulant factor. In addition, although there are potential advantages of nano-Se in living tissue, there are potential disadvantages of nano-Se also.

\section{Conclusions}

Based on all the information mentioned regarding the role of selenium, we can say that these materials can be important factors in increasing the resistance and the defensive ability of the intrinsic immunity in sheep. A selenium nanoparticle is more effective on the counts, survival duration, and the activity of neutrophils and increases them. The increase in TBARS value is longer and more severe when caused by sodium selenite than nano-selenium, which shows the better antioxidative effects of selenium nanoparticles. Since, in sheep, selenium nanoparticles were found to be less toxic and more bioactive than selenite, their use in feed instead of other forms of the element may be recommended.

Open Access This article is distributed under the terms of the Creative Commons Attribution Noncommercial License which permits any noncommercial use, distribution, and reproduction in any medium, provided the original author(s) and source are credited.

\section{References}

1. Navarro-Alarcon M, Lopez-Martinez MC (2000) Essentiality of selenium in the human body: relationship with different diseases. Sci Total Environ 249:347-371

2. El-Bayoumy K (2001) The protective role of selenium on genetic damage and on cancer. Mutat Res 475:123-139

3. Copeland PR (2003) Regulation of gene expression by stop codon recoding: selenocysteine. Gene 312:17-25

4. Driscoll DM, Copeland PR (2003) Mechanism and regulation of selenoprotein synthesis. Annu Rev Nutr 23:17-40

5. De Haan JB, Crack PJ, Flentjar N, Iannello RC, Hertzog PJ, Kola I (2003) An imbalance in antioxidant defense affects cellular function: the pathophysiological consequences of a reduction in antioxidant defense in the glutathione peroxidase-1 (Gpx1) knockout mouse. Redox Rep 8:69-79

6. Miyamoto Y, Koh YH, Park YS, Fujiwara N, Sakiyama H, Misonou Y, Ookawara T, Suzuki K, Honke K, Taniguchi N (2003) Oxidative stress caused by inactivation of glutathione peroxidase and adaptive responses. Biol Chem 384:567-574

7. Imai H, Nakagawa Y (2003) Biological significance of phospholipid hydroperoxide glutathione peroxidase (PHGPx, GPx4) in mammalian cells. Free Radic Biol Med 34:145-169

8. Nakagawa Y, Imai H (2000) Novel functions of mitochondrial phospholipid hydroperoxide glutathione peroxidase (PHGPx) as an anti-apoptotic factor. J Health Sci 46:414-417

9. Arner ESJ, Holmgren A (2000) Physiological functions of thioredoxin and thioredoxin reductase. Eur J Biochem 267:6102-6109

10. Becker K, Gromer S, Schirmer RH, Muller S (2000) Thioredoxin reductase as a pathophysiological factor and drug target. Eur J Biochem 267:6118-6125

11. Wang H, Zhang J, Yu H (2007) Elemental selenium at nano size possesses lower toxicity without compromising the fundamental effect on selenoenzymes: comparison with selenomethionine in mice. Free Radic Biol Med 42:524-1533

12. Xu B-H, Xu Z-L, Xia M-S (2003) Effect of nano red elemental selenium on GPx activity of broiler chick kidney cells in vitro. Wuhan Univ. J Nat Sci 8:1167-1172

13. Zhang JS, Wang HL, Yan XX, Zhang LD (2005) Comparison of short-term toxicity between nano-Se and selenite in mice. Life Sci 76:1099-1109

14. Zhang JS, Wang XF, Xu TW (2008) Elemental selenium at nano size (nano-Se) as a potential chemopreventive agent with reduced risk of selenium toxicity: comparison with Se-methylselenocysteine in mice. Toxicol Sci 101:22-31

15. Koracevic D, Koracevic G, Djordjevic V, Andrejevic S, Cosic V (2001) Method for the measurement of antioxidant activity in human fluids. J Clin Pathol 54:356-361

16. Zhang SY, Zhang J, Wang HY, Chen HY (2004) Synthesis of selenium nanoparticle in the presence of polysaccharides. Mater Let 58:2590-2594

17. Jain NC (1986) Schalm's veterinary hematology, 4th edn. Lea \& Febiger, Philadelphia, pp 381-383

18. Jain NC (1993) Essentials of veterinary hematology. Lea and Febiger, Philadelphia, pp 66-67

19. Segales J, Allan GM, Domingo M (2005) Porcine circovirus diseases. Anim Health Res Rev 6:119-142

20. Yu HJ, Liu JQ, Böck A, Li J, Luo GM, Shen JC (2005) Engineering glutathione transferase to a novel glutathione peroxidase mimic with high catalytic efficiency. J Biol Chem 280:11930-11935

21. Hamilton SJ (2004) Review of selenium toxicity in the aquatic food chain. Sci Total Environ 326:1-31

22. Armstrong D, Browne R (1998) Synthesis of lipid and cholesterol hydroperoxide standards, vol. 108. In: Free radical and antioxidant protocols. pp. 139-145 
23. Yagi A, Tsunoda M, Egusa T, Akasaki K, Tsuji H (1998) Immunochemical distinction of Aloe vera, A. arborescens, and A. chinensis gels. Planta Med 64:277-8

24. Kumar N, Garg AK, Mudgal V (2008) Effect of different levels of selenium supplementation on growth rate, nutrient utilization, blood metabolic profile, and immune response in lambs. Biol Trace Elem Res 126:S44-56

25. Huang B, Zhang J, Hou J, Chen C (2003) Free radical scavenging efficiency of nano-Se in vitro. Free Radic Biol Med 35:805-813

26. Bernard P, Negretti DE, Bratter VE (2000) Influence of high dietary selenium intake on the thyroid hormone level in human serum. J Trace Elemental Med Bio 20:163-166

27. Bickhardt K, Ganterm M, Sallmann P (1999) Investigation of the manifestation of vitamin $\mathrm{E}$ and selenium deficiency in sheep and goats. Deut Tierarztl Woch 106:242-247

28. Fraga CG, Ariass RF, Llesuy SF (1987) Effect of Vitamin E and Se deficiency on rat liver chemiluminescence. Biochem $G$ 242:383-392

29. Hodgson JC, Watkins CA, Bayne CW (2006) Contribution of respiratory burst activity to innate immune function and the effect of disease status and agent on chemiluminescence responses by ruminant phagocytes in vitro. Vet Immunol Immunopathol 112:12-23

30. Lessard M, Yang WC, Elliott GS (1991) Cellular immune response in pigs fed a vitamin E \& Se deficient diet. J Anim Sci 69:1575-1582

31. Heyland DK, Dhaliwal R, Suchner U (2005) Antioxidant nutrients: a systematic review of trace elements and vitamins in the critically ill patient. Intens Care Med 31:327-337

32. Hoekstra WG (1975) Biochemical function of selenium and it's relation to vitamin E. Fed Proc 34:2083-2090

33. Mazur A, Nasrri F, Rock E (1996) Diets deficient in selenium and vitamin $\mathrm{E}$ affect plasma lipoprotein and apo lipoprotein concentration in rat. J Nutr 76:899-907
34. Burk RF, Hill KE, Motley AK (2003) Selenoprotein metabolism and function: evidence for more than one function for selenoprotein. J Nutr 133:1517-1520

35. Zhou X, Wang Y, Gu Q, Li W (2009) Effects of different dietary selenium sources (selenium nanoparticle and selenomethionine) on growth performance, muscle composition and glutathione peroxidase enzyme activity of crucian carp (Carassius auratus gibelio). Aquaculture 291:78-81

36. Levander OA, Burk RF (1994) Selenium. In: Shils ME, Olson JA, Shike M (eds) Modern nutrition in health and disease. Lea and Febiger, Philadelphia

37. Sunde RA (2001) Regulation of selenoprotein expression. In: Hateld DL (ed) Se: its molecular biology and role in human health. Kluwer Academic Publishers, Dordrecht

38. Dong ZJ (2000) Selenium and fish nutrition: a review. J Shanghai Fisheries Univ 9:247-253

39. Hayes JD, Flanagan JU, Jowsey IR (2005) Glutathione transferases. Annu Rev Pharmacol Toxicol 45:51-88

40. Li H, Zhang J, Wang T, Luo W, Zhou Q, Jiang G (2008) Elemental selenium particles at nano-size (nano-Se) are more toxic to Medaka (Oryzias latipes) as a consequence of hyperaccumulation of selenium: a comparison with sodium selenite. Aquat Toxicol 89:251-256

41. Radostits OM, Gay CC, Hinchcliff KW (2007) Constable veterinary medicine: a textbook of the diseases of cattle, horses, sheep, pigs and goats, 10th ed. Saunders, Elsevier, Spain, pp 552557

42. Nandra RK (1997) Nutrition and the immune system: an introduction. Am Journal Clinical Nutrition 66:S460-S463

43. Pighetti GM, Eskew ML, Reddy CC, Sordillo LM (1998) Selenium and vitamin E deficiency impair transferrin receptor internalization but not IL-2, IL-2 receptor, or transferrin receptor expression. J Leukoc Biol 63:131-137 